\title{
The Optimal Cutoff Value of D-dimer Levels to Predict in Hospital Mortality in Severe Cases of Coronavirus Disease 2019
}

\author{
Ngakan Ketut Wira Suastika* (i), Ketut Suega ${ }^{2}$ iD \\ ${ }^{1}$ Department of Internal Medicine, Faculty of Medicine, Udayana University, Udayana University Hospital, Bali, Indonesia; \\ ${ }^{2}$ Department of Internal Medicine, Faculty of Medicine, Udayana University, Sanglah General Hospital, Bali, Indonesia
}

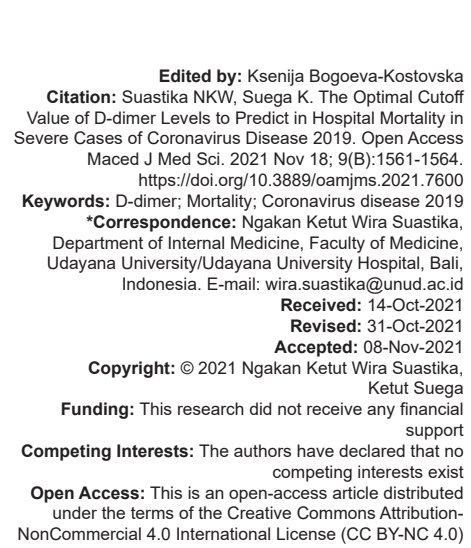

Introduction

Coronavirus disease 2019 (COVID-19) has spread globally. There have been more than 30 million confirmed cases with more than 600 thousands of deaths until September 2020 [1]. Risk stratification is necessary to provide faster and more precise patient management. Laboratory markers that can predict mortality are needed, so the risk stratification in COVID19 patients can be done.

D-dimers are derived from cross-linked fibrin lysis which indicates the activation of the coagulation and fibrinolysis processes. In clinical practice, D-dimers are used to rule out pulmonary embolism or deep vein thrombosis (DVT) [2]. Coagulation function abnormalities occur in severe COVID19 cases and are associated with an increased risk of mortality [3], [4]. Rapid deterioration of clinical conditions occurs in patients with significant elevation in D-dimers [5]. Pulmonary embolism should be considered in patients with respiratory distress, a rapid decrease in oxygen saturation (SpO2), and a rapid decrease of blood pressure [6].

This study aims to determine the difference of D-dimer levels in severe patients of COVID-19 who survive and non-survive and the optimal cutoff value of D-dimer level to predict mortality.

\section{Methods}

\section{Study participants and design}

This study is a prospective study conducted at the Udayana University Hospital, Bali, Indonesia, which is designated as a hospital that specializes in treating COVID-19 patients in Bali province. The diagnosis of COVID-19 is based on a nasopharyngeal swab examination using the real-time reverse transcriptasepolymerase chain reaction method. The criteria for severe COVID-19 cases are based on interim guidelines issued by the World Health Organization, including patients with pneumonia clinical signs such as dyspnea, cough, fever, and rapid breathing, plus one of the following: Severe respiratory distress, respiratory rate more than 30 breaths per minute, or partial SpO2 $<90 \%$ in room air [7]. Patients under 18 years old and pregnant patients were not recruited in this study. This study has been approved by the Committee of Ethics of the Medical Faculty of Udayana University (1010/UN14.2.2.VII.14/LT/2020). 
Table 1: Epidemiological characteristics, complete blood count, and coagulation profile

\begin{tabular}{|c|c|c|c|c|}
\hline \multirow[t]{2}{*}{ Variable } & \multicolumn{4}{|c|}{ Median (minimum-maximum) } \\
\hline & All patients $(n=80)$ & Survivors $(n=70)$ & Non-survivors $(n=10)$ & $p$-value \\
\hline Age, years & $56.0(22-82)$ & $54.0(22-82)$ & $62.5(44-72)$ & 0.386 \\
\hline \multicolumn{5}{|l|}{ Sex } \\
\hline Male (\%) & $60(75)$ & $52(74.3)$ & $8(80)$ & 0.521 \\
\hline Female (\%) & $20(25)$ & $18(25.7)$ & $2(20)$ & \\
\hline Hemoglobin $\mathrm{g} / \mathrm{dl}$ & $13.3(7.9-17.1)$ & $13.3(7.9-17.1)$ & $13.4(11.6-15.2)$ & 0.668 \\
\hline Leukocytes, $\times 10^{3} \mu \mathrm{L}$ & $7.89(3.81-17.25)$ & $7.57(3.81-15.98)$ & $9.75(6.63-17.25)$ & 0.035 \\
\hline Neutrophil, $\times 10^{3} \mu \mathrm{L}$ & $5.81(2.56-15.50)$ & $5.77(2.56-13.78)$ & $8.11(5.03-15.50)$ & 0.019 \\
\hline Lymphocyte, $\times 10^{3} \mu \mathrm{L}$ & $1.02(0.28-5.70)$ & $1.04(0.28-5.70)$ & $0.70(0.31-1.53)$ & 0.367 \\
\hline Monocyte, $\times 10^{3} \mu \mathrm{L}$ & $0.59(0.05-1.64)$ & $0.57(0.15-1.64)$ & $0.65(0.05-1.15)$ & 0.517 \\
\hline Platelet, $\times 10^{3} \mu \mathrm{L}$ & $274(95-672)$ & $272(95-672)$ & $275(195-446)$ & 0.684 \\
\hline NLR & $5.84(1.40-32.94)$ & $5.56(1.40-32.94)$ & $9.31(5.19-29.8)$ & 0.018 \\
\hline D-dimer, $\mu \mathrm{g} / \mathrm{ml}$ & $1.307(0.302-50.000)$ & $1.201(0.302-29.425)$ & $3.346(0.939-50.000)$ & 0.010 \\
\hline APTT, second & $25.80(18.80-47.70)$ & $26.60(18.80-47.70)$ & $24.70(18.80-41.00)$ & 0.624 \\
\hline PT, second & $8.90(8.10-23.7)$ & $8.90(8.10-10.00)$ & $9.20(8.50-23.70)$ & 0.033 \\
\hline INR & $0.87(0.81-1.97)$ & $0.87(0.81-0.96)$ & $0.92(0.83-1.97)$ & 0.007 \\
\hline
\end{tabular}

\section{Data collection}

Data were obtained through patient medical records, including clinical, epidemiological, and laboratory data, then the patient was followed and the clinical outcome was recorded whether survival or non-survival. Blood samples were obtained when the patient was admitted to the hospital. Examination of D-dimer levels in this study used an automatic coagulation analyzer Sysmex CS 5100, Japan. The levels of D-dimer are expressed in $\mu \mathrm{g} / \mathrm{ml}$ fibrinogen equivalent unit.

\section{Statistical analysis}

Categorical variables are expressed in percentage while numerical variables are presented in the median (minimum-maximum). We divided patients into two categories: Non-survivors and survivors. The Mann-Whitney $U$ test was used to determine differences in numerical variables and Fisher's exact tests were used for categorical variables. The optimal cutoff value, area under the curve (AUC), sensitivity, and specificity of D-dimer levels in predicting mortality were obtained by the receiver operating characteristic curve (ROC) method. The results obtained were statistically significant if $p<0.05$. The Statistical Package for the Social Sciences version 18.0 software is used for statistical calculations.

\section{Results}

Epidemiological characteristics, complete blood count, and coagulation parameters

A total of 80 patients were recruited in this study. Table 1 shows epidemiological characteristics, complete blood count, and coagulation parameters. A total of 70 patients $(87.5 \%)$ survived, while ten patients $(12.5 \%)$ did not survive. There were significant differences in leukocytes, absolute neutrophil count, neutrophil to lymphocyte ratio, prothrombin time, international normalized ratio, and D-dimer in surviving and non-surviving patients. Meanwhile, there were no significant differences in age, sex, hemoglobin levels, absolute lymphocyte and monocyte count, platelets, and activated partial thromboplastin time.

\section{Optimal cutoff values, sensitivity,} specificity, and area under curve

Using the ROC method, we found the optimal cutoff value for levels of D-dimer to predict mortality was above $1.500 \mu \mathrm{g} / \mathrm{ml}$, with $80.0 \%$ sensitivity, $64.3 \%$ specificity, and AUC $0.754(95 \% \mathrm{Cl}$ 0.586-0.921; $p=0.010)$ (Figure 1 and Table 2).

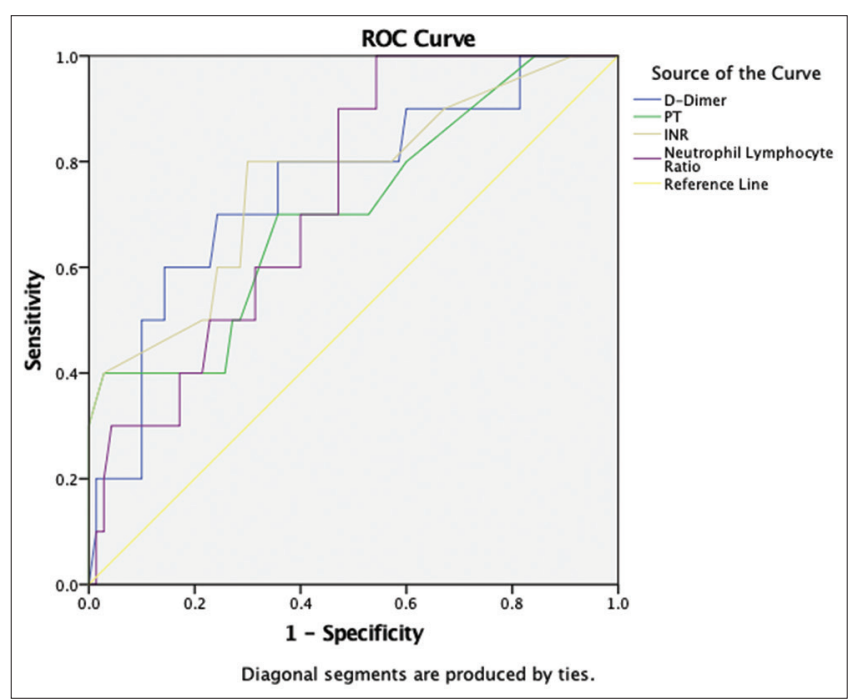

Figure 1: The receiver operating characteristic curve analysis to find the diagnostic value of $D$-dimer, prothrombin time, and international normalized ratio to predict mortality in severe cases of coronavirus disease 2019

Table 2: Diagnostic values of D-dimer, PT, and INR to predict mortality in severe cases of COVID-19

\begin{tabular}{|c|c|c|c|c|c|c|}
\hline Variable & Cutoff value & Sensitivity, \% & Spesificity, \% & AUC & $95 \%$ confidence interval & p-value \\
\hline D-dimer, $\mu \mathrm{g} / \mathrm{ml}$ & 1.500 & 80.0 & 64.3 & 0.754 & $0.586-0.921$ & 0.010 \\
\hline $\mathrm{PT}$, second & 9.0 & 70.0 & 64.3 & 0.707 & $0.524-0.890$ & 0.035 \\
\hline INR & 0.87 & 80.0 & 70.0 & 0.763 & $0.591-0.935$ & 0.007 \\
\hline NLR & 6.8 & 70.0 & 60.0 & 0.733 & $0.594-0.872$ & 0.018 \\
\hline
\end{tabular}




\section{Discussion}

This study found that levels of D-dimer were significantly higher in non-surviving compared to surviving patients. This is in accordance with the study of Tang et al. who found that there was a significant difference in D-dimer levels in non-surviving versus surviving patients [3]. Abnormalities of coagulation function parameters such as elevated D-dimers are associated with disease progression [8]. The cohort study showed that coagulation function parameters such as PT and D-dimer were significantly elevated in severe COVID-19 which means that impaired coagulation function is associated with severity of the disease [6]. D-dimer levels were also significantly higher in patients treated in intensive care unit (ICU) compared to nonICU patients [9]. Elevated D-dimer levels are also associated with mortality and administration of the low molecular weight heparin therapy can reduce the rate of mortality [10]. Agreater precaution for thromboembolism should be given to severe COVID-19 patients who are immobilized and have abnormal coagulation function parameters [9], [11].

This study found that level of D-Dimer higher than $1.500 \mu \mathrm{g} / \mathrm{ml}$ is the optimal cutoff value for predicting mortality in severe cases of COVID-19. A study by Zhang et al. found that levels of D-dimer on admission to the hospital of more than $2.0 \mu \mathrm{g} / \mathrm{ml}$ were a predictor of mortality. Hence, in patients with an increase in D-dimer above $2 \mu \mathrm{g} / \mathrm{ml}$ or 4 times the normal value, close care and monitoring are required in the hospital even though they do not show severe symptoms [5]. This is in accordance with the guidelines for the management of coagulopathy in COVID-19 issued by the International Society of Thrombosis and Hemostasis [12]. A study by Zhou et al. on 191 patients of COVID-19 found that D-dimer levels of more than $1 \mu \mathrm{g} / \mathrm{ml}$ on admission were associated with mortality [4]. Levels of D-dimer of more than $1.570 \mu \mathrm{g} / \mathrm{ml}$ in patients of COVID-19 are associated with asymptomatic DVT [13].

D-dimers are a less specific marker for assessing the occurrence of thrombosis [2]; however, D-dimer can be used to predict prognosis in patients of COVID-19 [5], [14]. Elevated levels of D-dimer are an indication of a hypercoagulable state in COVID-19 patients. This can be caused by several factors; the viral infection itself can cause an aggressive inflammatory response [15]. Increase in inflammatory cytokines can activate the fibrinolysis system in the alveoli [16]. Inflammation can also cause endothelial cell dysfunction which will increase the formation of thrombin [17]. Hypoxia that occurs in severe COVID-19 patients can stimulate thrombosis due to increased blood viscosity [18]. Severe COVID-19 patients who are hospitalized are mostly elderly, with comorbid diseases, reduced mobility, and with invasive therapy, all of which are risk factors for thrombosis [19], [20], [21].
Elevated of D-dimer levels in patients with COVID-19 can also be caused by sepsis-induced coagulopathy and disseminated intravascular coagulation [22]. However, the study by Yu et al. found that levels of D-dimer were correlated more with inflammatory markers and there is no significant correlation between levels of $D$-dimer and venous thromboembolism scores. This suggests that it is not appropriate to administer anticoagulant therapy based solely on D-dimer levels in COVID-19 patients. Mismatch between levels of D-dimer and inflammatory markers such as high-sensitivity c-reactive protein (hsCRP) can be used as an indicator of the need for anticoagulant therapy [23].

This study has several limitations, including it being a relatively small sample and a single center study although it can provide statistically significant results. Some patients were not recruited in this study because they did not have their D-dimer levels on admission. The disease onset is different for each patient, so it may affect the D-dimer level that is checked at the time the patient is admitted to the hospital.

\section{Conclusions}

Levels of D-dimer were significantly higher in non-surviving patients of COVID-19 compared to survivors. D-dimer levels of more than $1.500 \mu \mathrm{g} / \mathrm{ml}$ are associated with a higher chance of mortality, so it can be used as a biomarker to increase alertness in the management of severe COVID-19 patients.

\section{Acknowledgments}

The author gives the highest appreciation to all medical personnel at the Udayana University Hospital, Bali, Indonesia.

\section{References}

1. World Health Organization. Coronavirus Disease (COVID-19) Outbreak. Emergencies Diseases. Available from: https://www. who.int/emergencies/diseases/novel-coronavirus-2019. [Last accessed on 2020 Sep 30].

2. Zhang L, Long $\mathrm{Y}$, Xiao $\mathrm{H}$, Yang J, Toulon $\mathrm{P}$, Zhang Z. Use of D-dimer in oral anticoagulation therapy. Int $\mathrm{J}$ Lab Hem. 2018;40(5):503-7. https://doi.org/10.1111/ijlh.12864 PMid:29806239

3. Tang N, Li D, Wang X, Sun Z. Abnormal coagulation parameters are associated with poor prognosis in patients with novel coronavirus pneumonia. J Thromb Haemost. 2020;18(4):844-7. 
https://doi.org/10.1111/jth.14768

PMid:32291954

4. Zhou F, Yu T, Du R, Fan G, Liu Y, Liu Z, et al. Clinical course and risk factors for mortality of adult inpatients with COVID-19 in Wuhan, China: A retrospective cohort study. Lancet. 2020;395(10299):1054-62. https://doi.org/10.1016/ S0140-6736(20)30566-3

PMid:32171076

5. Zhang L, Yan X, Fan Q, Liu H, Liu X, Liu Z, et al. D-dimer levels on admission to predict in-hospital mortality in patients with Covid-19. J Thromb Haemost. 2020;18(6):1324-9. https://doi. org/10.1111/jth.14859

PMid:32306492

6. Yu HH, Qin C, Chen M, Wang W, Tian DS. D-dimer level is associated with the severity of COVID-19. Thromb Res. 2020;195:219-25. https://doi.org/10.1016/j. thromres.2020.07.047 PMid:32777639

7. World Health Organization. Clinical Management of Severe Acute Respiratory Infection (SARI) when COVID-19 Disease is Suspected: Interim Guidance, 27 May 2020. Geneva: World Health Organization; 2020.

8. Han H, Yang L, Liu R, Liu F, Liu F, Wu KL, et al. Prominent changes in blood coagulation of patients with SARS-CoV-2 infection. Clin Chem Lab Med. 2020;58(7):1116-20. https://doi org/10.1515/cclm-2020-0188

PMid:32172226

9. Huang C, Wang Y, Li X, Ren L, Zhao J, Hu Y, et al. Clinical features of patients infected with 2019 novel coronavirus in Wuhan, China. Lancet. 2020;395(10223):497-506. https://doi. org/10.1016/S0140-6736(20)30183-5 PMid:31986264

10. Tang N, Bai H, Chen X, Gong J, Li D, Sun Z. Anticoagulant treatment is associated with decreased mortality in severe coronavirus disease 2019 patients with coagulopathy. J Thromb Haemost. 2020;18(5):1094-9. https://doi.org/10.1111/jth.14817 PMid:32220112

11. Chen N, Zhou M, Dong $X, Q u$ J, Gong F, Han $Y$, et al. Epidemiological and clinical characteristics of 99 cases of 2019 novel coronavirus pneumonia in Wuhan, China: A descriptive study. Lancet. 2020;395(10223):507-13. https://doi.org/10.1016/ S0140-6736(20)30211-7

PMid:32007143

12. Thachil J, Tang N, Gando S, Falanga A, Cattaneo M, Levi M, et al. ISTH interim guidance on recognition and management of coagulopathy in COVID-19. J Thromb Haemost. 2020;18(5):1023-6. https://doi.org/10.1111/jth.14810 PMid:32338827

13. Demelo-Rodríguez $\mathrm{P}$, Cervilla-Muñoz $\mathrm{E}$, Ordieres-Ortega $\mathrm{L}$, Parra-Virto A, Toledano-Macías M, Toledo-Samaniego N, et al. Incidence of asymptomatic deep vein thrombosis in patients with COVID-19 pneumonia and elevated D-dimer levels. Thromb Res. 2020;192:23-6. https://doi.org/10.1016/j. thromres.2020.05.018

PMid:32405101

14. Long $\mathrm{H}$, Nie L, Xiang $\mathrm{X}$, Li H, Zhang $\mathrm{X}$, Fu X, et al. D-Dimer and Prothrombin Time Are the Significant Indicators of Severe COVID-19 and Poor Prognosis. Biomed Res Int. 2020;2002:6159720. https://doi.org/10.1155/2020/6159720 PMid:32596339

15. Wong JP, Viswanathan S, Wang M, Sun LQ, Clark GC, D'elia RV. Current and future developments in the treatment of virusinduced hypercytokinemia. Future Med Chem. 2017;9(2):16978. https://doi.org/10.4155/fmc-2016-0181 PMid:28128003

16. Li XY, Du B, Wang YS, Kang HY, Wang F, Sun B, et al. The keypoints in treatment of the critical coronavirus disease 2019 patient (1). Chin J Resp Dis. 2020;43(4):273-277. https:// doi.org/10.3760/cma.j.cn112147-20200222-00151 PMid:32087621

17. Levi M, van der Poll T. Coagulation and sepsis. Thromb Res. 2017;149:38-44. https://doi.org/10.1016/j.thromres.2016.11.007 PMid:7886531

18. Gupta N, Zhao YY, Evans CE. The stimulation of thrombosis by hypoxia. Thromb Res. 2019;181:77-83. https://doi.org/10.1016/j. thromres.2019.07.013

PMid:31376606

19. Harper PL, Theakston E, Ahmed J, Ockelford P. D-dimer concentration increases with age reducing the clinical value of the D-dimer assay in the elderly. Intern Med J. 2007;37(9):60713. https://doi.org/10.1111/j.1445-5994.2007.01388.x PMid: 17543005

20. Barbar S, Noventa F, Rossetto V, Ferrari A, Brandolin B, Perlati M, et al. A risk assessment model for the identification of hospitalized medical patients at risk for venous thromboembolism: The Padua Prediction Score. J Thromb Haemost. 2010;8(11):24507. https://doi.org/10.1111/j.1538-7836.2010.04044.x PMid:20738765

21. Hess K, Grant PJ. Inflammation and thrombosis in diabetes. J Thromb Haemost. 2011;105(S06):S43-54. https://doi. org/10.1160/THS10-11-0739 PMid:21479339

22. Iba T, Levy JH, Warkentin TE, Thachil J, van der Poll T, Levi M. Diagnosis and management of sepsis-induced coagulopathy and disseminated intravascular coagulation. J Thromb Haemost. 2019;17(11):1989-94. https://doi.org/10.1111/jth.14578 PMid:31410983

23. Yu B, Li X, Chen J, Ouyang M, Zhang H, Zhao X, et al. Evaluation of variation in D-dimer levels among COVID-19 and bacterial pneumonia: A retrospective analysis. J Thromb Thrombolysis. 2020;50:548-57. https://doi.org10.1007/s11239-020-02171-y 